\title{
Uso de diferentes métodos no controle do desenvolvimento do Staphylococcus aureus: uma revisão da literatura
}

\author{
Use of different methods to control the development of Staphylococcus aureus: a literature review
}

Uso de diferentes métodos para controlar el desarrollo de Staphylococcus aureus: una revisión de la literatura

\section{Resumo}

Staphylococcus aureus é uma bactéria patogênica que pode causar várias doenças em seres humanos e animais. O uso de antibióticos no controle do seu desenvolvimento tem sido muitas vezes ineficiente tendo em vista sua capacidade de tornar-se resistente a estas substâncias. Assim, a busca por novas alternativas eficazes no combate deste microrganismo é um desafio para ciência e tem se tornando extremamente relevante. Este estudo objetivou analisar na literatura o uso de diferentes substâncias, naturais e químicas, no controle do desenvolvimento do S. aureus isolados de diferentes fontes. Para composição deste estudo foram utilizados livros, dissertações, teses e artigos científicos das bases de dados Google acadêmico, Scielo e Science direct. Os trabalhos foram selecionados de forma austera, conforme o conteúdo do título e/ou resumo. Com base nos resultados concluiu-se que o uso de antibióticos, apesar de ser uma forma eficiente para o controle do desenvolvimento do $S$. aureus, seu uso deve ser controlado em virtude da possível ocorrência de cepas resistentes a estas substancias. Outras possibilidades para o controle desse microrganismo têm apresentado eficiência, como o uso de óleos essenciais, extrato de plantas, biofilmes, filmes a base de gelatina, controle biológico por bacteriófagos líticos e ozonioterapia. Contudo, para uso destas substâncias, maiores estudos devem ser realizados. Palavras-chave: Bactérias; Patogênica; Resistência; Sensibilidade.

\begin{abstract}
Staphylococcus aureus is a pathogenic bacterium that can cause many diseases in humans and animals. The use of antibiotics to control their development has often been inefficient owing to their ability to become resistant to these substances. Thus, a search for new effective alternatives to combat this microorganism is a challenge for science and has become extremely relevant. This study aimed to analyze in the literature the use of different substances, natural and chemicals, in the control of the development of $S$. aureus from different sources. For this study, books, dissertations, thesis and scientific articles from the Google academic, Scielo and Science direct databases were used. The works were selected austerely, according to the content of the title and / or abstract. Based on the results found that the use of antibiotics, despite being an efficient way to control the development of $S$. aureus, their use must be controlled due to
\end{abstract}


the occurrence of resistant strains to these substances. Other possibilities for the control of this microorganism have shown efficiency, such as the use of essential oils, plant extracts, biofilms, gelatin-based films, biological control by lytic bacteriophages and ozone therapy. However, to use these substances, further studies must be performed.

Keywords: Bacteria; Pathogenic; Resistance; Sensitivity.

\section{Resumen}

Staphylococcus aureus es una bacteria patógena que puede causar diversas enfermedades en humanos y animales. El uso de antibióticos para controlar su desarrollo a menudo ha sido ineficaz en vista de su capacidad para volverse resistentes a estas sustancias. Así, la búsqueda de nuevas alternativas alternativas para combatir este microorganismo es un desafío para la ciencia y se ha vuelto de suma relevancia. Este estudio tuvo como objetivo analizar la literatura el uso de diferentes sustancias, naturales y compuestos, en el control del desarrollo de S. aureus fue de diferentes fuentes. Para este estudio se utilizaron libros, disertaciones, tesis y artículos científicos de las bases de datos académica de Google, Scielo y Science Direct. Las obras fueron seleccionadas de forma austera, según el contenido del título y / o resumen. Con base en los resultados se encontró que el uso de antibióticos, a pesar de ser una forma eficaz de controlar el desarrollo de S. aureus, debe controlarse su uso debido a la aparición de cepas resistentes a estas sustancias. Otras posibilidades para el control de este microorganismo han mostrado eficácia, como el uso de aceites esenciales, extractos de plantas, biopelículas, películas a base de gelatina, control biológico por bacteriófagos líticos y ozonoterapia.. Sin embargo, para utilizar estas sustancias, se deben realizar más estudiosIncluir o resumo em espanhol.

Palabras clave: Bacterias; Patógeno; Resistencia; Sensibilidad.

\section{Introdução}

O Staphylococcus aureus é uma bactéria gram positiva pertencente ao gênero Staphylococcus e à família Staphylococcaceae. Geralmente se agrupam em formato de cocos com a aparência de cachos de uva. São imóveis, não esporogênicos, catalase positiva e oxidade usualmente negativa. Por serem quimioorganotróficos, apresentam metabolismo de carboidratos respiratórios e fermentativos. São susceptíveis à lise por lisostafina e resistentes à lisozima. Predominantemente associados à pele, glândulas e mucosas de animais de sangue quente (Silva, Junqueira, Silveira, Taniwaki, Gomes, \& Okazaki, 2017).

O diâmetro da sua célula situa-se entre 0,5 e 1,5 $\mu \mathrm{m}$ e, pelo menos, 11 sorotipos possuem em sua estrutura cápsula de natureza polissacarídea, onde os sorotipos 6 e 7 são os mais associados às infecções em seres humanos. São aeróbios ou anaeróbios facultativos, e crescem em ambientes a temperaturas estabelecidas entre 18 e $40^{\circ} \mathrm{C}$ e com elevado teor de cloreto de sódio (10\%) (Costa, 2018). O S. aureus é a principal espécie do grupo de Staphylococcus spp. coagulase positiva (SCP) e é um patógeno frequentemente associado à mastite contagiosa bovina (Gasparotto et al., 2016).

Fazem parte da microbiota humana e podem provocar doenças que vão desde uma infecção simples, como espinhas e furúnculos, até as mais graves, como pneumonia, meningite, endocardite, síndrome do choque tóxico e septicemia. Nos seres humanos, são as bactérias mais frequentemente encontradas na mucosa nasal, a partir das quais contamina as mãos, desempenhando papel importante na disseminação de infecções através dos alimentos (Almeida, Mendonça, Freitas, \& Vandesmet, 2016). Sua grande interação e adaptação ao homem, animal e meio ambiente e sua fácil aquisição de genes responsáveis por potencializar seus fatores de patogenicidade os transformam em um grande problema de saúde pública (Souza et al., 2017).

Por serem classificados como um dos principais agentes patogênicos causadores de enfermidades ligadas aos animais (Barrera-Rivas et al., 2017) e humanos (Alegre et al., 2016), a busca por opções para o controle do seu desenvolvimento utilizando métodos alternativos vêm sendo bastante pesquisado. Ressalta-se que o uso incorreto de antibióticos convencionais, atualmente a maneira mais usualmente utilizada para o controle desse microrganismo, pode estar relacionada a resistência bacteriana. Esta revisão de literatura tem como objetivo analisar nas bibliografias o uso de diferentes substancias no controle do desenvolvimento do S. aureus isolados de diferentes fontes. 


\section{Metodologia}

Trata-se de um estudo caracterizado como uma Revisão Integrativa da Literatura (RIL), que possibilita a identificação, síntese e a realização de uma análise ampla na literaturaacerca de uma temática específica (Silva et al., 2020 como citado em Pereira et al, 2020, p.5). O presente estudo apresentou-se como descritivo de caráter analítico acerca do microrganismo staphylococcus aureus, com foco no seu controle através de antibióticos e substancias alternativas.

A coleta de dados foi realizada no período de 10 de novembro a 20 de dezembro de 2020. Os trabalhos científicos utilizados nesta revisão foram retirados de diferentes bases de dados: Google académico, Scielo e Science Direct, além do uso de livros e dissertações de graduação e mestrado. Os critérios de inclusão utilizados para a busca foram artigos publicados com recorte temporal de 2006 a 2020. A busca dos artigos científicos se deu em uma primeira fase empregando-se os seguintes descritores em português e inglês: Staphyloccocus aureus, resistência microbiana, mastite, substancias usadas para o controle do Staphyloccocus aureus. A seleção dos artigos foi ponderada por meio dos títulos dos trabalhos, bem como dos resumos dos trabalhos a fim de se verificar se os mesmos abrangiam o intuito desta revisão. Não foi limitado idioma na tentativa de obter quantidade relevante de referencial teórico. Foram obtidas 69 fontes, das quais 32 foram selecionadas e utilizadas. Dessa forma, foram utilizadas as seguintes etapas para sua elaboração: delimitação do tema e construção da pergunta norteadora da pesquisa; levantamento das publicações nas bases de dados selecionadas; classificação e análise das informações achadas em cada manuscrito; análise dos estudos escolhidos; apresentação dos resultados encontrados e inclusão, análise crítica dos achados e síntese da revisão da literatura (Souza et al., 2010 como citado em Pereira et al, 2020, p.5).

\section{Antibióticos no Controle do Staphylococcus aureus: Pontos Positivos e Negativos}

Antibióticos podem ser definidos como compostos naturais ou sintéticos capazes de inibir o crescimento ou causar a morte de fungos ou bactérias (Guimarães, Momesso, \& Pupo, 2010). Estas substâncias podem apresentar duas funções distintas: a inibição do crescimento bacteriano através da ação bacteriostática e a destruição de uma população bacteriana, por uma ação bactericida. A ação bacteriostática impede o crescimento das bactérias, mantendo o mesmo na fase estacionária (Pankey \& Sabath, 2013 como citado em Baptista, 2013, p. 1), O efeito bactericida, por sua vez, atua em processos vitais para a célula levando à morte celular (Goodman \& Gilman's, 2008, Katzung, 2007, Lago, 2011, como citado em Baptista, 2013, p. 1).

Antibióticos em geral, são considerados indispensáveis à manutenção da saúde humana e animal. Entretanto, não podemos superestimá-los e acreditar que sua utilização é a única forma para o controle de todas as doenças. No Brasil, o uso inapropriado dessas substâncias em seres humanos e em animais é um problema de difícil controle. A aquisição destes medicamentos em farmácias ou em casas agropecuárias, de forma ilegal e/ou sem prescrição médica ou de um médico veterinário, é algo bastante comum. Assim, estima-se que 20 a 50\% do uso de antimicrobianos em seres humanos e 40 a $80 \%$ em animais seja desnecessário ou altamente questionável (Beovic, 2006).

De acordo com Arias e Carrilho (2012), a resistência aos agentes antimicrobianos tornou-se uma das principais preocupações para a saúde humana e veterinária. Desta forma, sabendo-se que a utilização indiscriminada de antibióticos convencionais pode favorecer a seleção de bactérias resistentes, o que gera prejuízos a toda a cadeia produtiva e a saúde pública (Ribeiro, 2015), doenças que seriam facilmente controladas, não poderão ser tratadas com tanta facilidade. O fato de diversas classes de antimicrobianos usadas em animais também serem empregadas em seres humanos para tratar doenças graves reforça que o uso incorreto de antimicrobianos nestes animais pode contribuir para o desenvolvimento de resistência antimicrobiana em humanos.

Considerando ainda que a maioria destes animais e seus subprodutos serão destinados ao consumo humano, existe ainda uma grande possibilidade de essas cepas multirresistentes serem transmitidas e incorporadas à microbiota humana, reduzindo a eficácia dos antimicrobianos (Chantziaras, Boyen, Callens \& Dewulf, 2013). Costa (2018) ressalta que cepas de Staphylococcus 
aureus são particularmente perigosas tanto pelo fato de se tornarem facilmente resistente a antibióticos usados comumente na prática clínica como pela sua forte e rápida disseminação a nível global.

Ao analisarem a sensibilidade a antibióticos de microrganismos isolados de brinquedos de hospitais, Boretti, Corrêa, Santos, Ferreira dos \& Silva (2014) observaram que o uso de Vancomicina teve melhores resultados no combate ao desenvolvimento destes microrganismos. Esses medicamentos têm se tornado um dos fármacos de primeira linha no tratamento de infecções por bactérias Gram positivas com resistência a diversos antibióticos (Guimarães, Momesso, \& Pupo, 2010). Em contrapartida, outros antibióticos como claritromicina, clindamicina, oxacilina e penicilina em relação ao S. aureus tiveram respectivamente $28,6 \%, 35,7 \%, 21,4 \%$ e $71,4 \%$ de resistência, corroborando com o que tem sido apresentado por outros autores no que tange a diferentes níveis de resistência a maioria dos antibióticos.

A alta prevalência de isolados multirresistentes a antibióticos reforça a preocupação atual com a disseminação de bactérias resistentes na cadeia produtiva de alimentos (Silva, Iacuzio, Cândido, Rodrigues \& Silva, 2018). Diante disso vários autores têm relatado em seus estudos que cepas de $S$. aureus tem demostrado resistências a diferentes antibióticos reforçando que o uso de antibióticos muitas vezes pode não ser eficaz para o tratamento de patogenias caudadas por estes microrganismos.

Em um estudo recente realizado com cepas isoladas do leite de vaca com mastite, Lima et al. (2020), observaram que o agente etiológico envolvido em maiores percentuais foi S. aureus, a resistência causada pelo uso dos antibióticos faz com que a essa doença tenha o tratamento dificultado, ocasionando inclusive a mastite crônica, ressaltando a importância de se realizar os testes diagnóstico. Estes autores reportaram que os agentes bacterianos isolados em sua maioria mostraram alta frequência de resistência frente antibióticos composto por bacitracina, sulfonamidas e penicilina G.

A presença de resíduos de antibióticos, especialmente em produtos lácteos, é outro fator resultante da aplicação indiscriminada e/ou de maneira incorreta dos antibióticos, sem aguardar o período de carência. O tratamento para infecção intramamária, conhecida como mastite, que é feito pela aplicação do produto de uso veterinário pela via intramamária é sem dúvida o principal responsável pelos resíduos antimicrobianos no leite (Silva et al., 2013). Esse tipo de contaminação está correlacionado a saúde humana pois a ingestão destas substâncias pode vir a ocasionar diversos danos como processos de hipersensibilidade, teratogênese (Desenvolvimento, no útero, de anomalias que levam a malformações), alteração da microbiota intestinal prejudicando sua ação gastromucoprotetora, além de resultar na seleção das populações de bactérias altamente resistentes (Pereira \& Scussel, 2016).

Outro fator que pode ser considerado como um ponto negativo ao uso de antibióticos no combate a microrganismos relaciona-se ao alto custo dos antibióticos. Isto o torna um fator limitante para o tratamento de algumas doenças, principalmente as doenças que afetam os animais de produção, como a mastite. Zafalon, Filho, Oliveira \& Resende (2007) em seu estudo observou que o tratamento da mastite subclínica causada por $S$. aureus, durante a lactação, realizado com gentamicina intramamária, não resultou em aumento da produção de leite dos quartos tratados em comparação com a dos quartos sadios, revelando que mesmo com o alto custo do medicamento, não ocorreu ganhos positivos para a produção, para justificar tal gasto.

\section{Utilização de Métodos Alternativos no Controle do Desenvolvimento do Staphylococcus aureus}

A busca por novas alternativas que sejam eficazes no controle do desenvolvimento do Staphylococcus spp. tem sido um grande desafio para os pesquisadores. Atualmente existem vários estudos que buscam formas de substituir o uso de antibióticos por substancias que sejam eficientes e que tenham bom custo benefício. Óleos essenciais (OES), extrato de plantas, biofilmes, filmes a base de gelatina, controle biológico por bacteriófagos líticos e ozonioterapia são métodos, que estão sendo estudados por diversos autores, para o controle alternativos do desenvolvimento destas bactérias.

A utilização de plantas medicinais, e de seus óleos essenciais se propagaram consideravelmente possibilitando assim novas formas de tratamento, podendo ser mais eficientes e/ou mais acessível. As utilizações de extratos vegetais por sua vez 
também se tornaram promissoras visto que reduz a seleção de microrganismos multirresistentes e não acumulam resíduos nos alimentos (Ribeiro, 2015).

Os óleos essenciais são metabólitos secundários dos vegetais com propriedades biológicas diferenciadas, dentre elas, a atividade antimicrobiana (Millezi, et al., 2014). Muitos Óleos essenciais têm demonstrado eficiência contra patógenos alimentares e microrganismos deteriorantes e patogênicos (Bassanetti et al., 2017). Silva et al. (2018) identificaram o perfil de resistência antimicrobiana de Staphylococcus aureus isolados de frangos utilizando diferentes antibióticos e óleos essenciais de alecrim, capim- e pimenta preta. Neste estudo os autores perceberam uma elevada prevalência de isolados multirresistentes a antibióticos em contrapartida. Isolados encontrados neste mesmo estudo foram avaliados quanto à resistência frente a óleos essenciais e obtiveram os resultados positivos para os OES alecrim e de capim limão.

O óleo de alecrim-pimenta também apresentou efeito microbicida, contra o S. aureus, no estudo realizado por Souza et al. (2017) demonstrando o potencial dessas plantas como utilização alternativa aos antibióticos. Monteiro (2017) por sua vez, verificou que o óleo de andiroba puro não apresentou atividade antimicrobiana nas cepas do mesmo microrganismo. Podemos perceber que existem uma grande variedade de OES em estudos, alguns com resultados positivos para o controle do S. aureus, outros não, reforçando assim a importância de pesquisas nessa área.

Os extratos vegetais podem ser promissores como alternativas para substituir os antimicrobianos convencionais (Ribeiro, 2015). Estas substancias apresentam diferentes formas de ação para inibição bacteriana que estão relacionadas com os compostos secundários produzidos pelas plantas e apresentam diferenças para cada espécie vegetal. Castro et al. (2015) realizou um estudo sobre a composição química e eficácia do extrato etanólico (EE) de Alpinia zerumbet sobre cepas de Staphylococcus aureus, s isoladas de vacas com mastite subclínica e cepas padrão American Type Culture Collection (ATCC) 29213 e ATCC 25923. O EE das folhas de A. zerumbet possuíram ação significativa contra este microrganismo, podendo assim ser considerada como uma fonte de novos compostos antibacterianos para o controle da mastite bovina.

Ribeiro (2015) em seu estudo observou que cepas de $S$. aureus foram sensíveis aos cinco extratos selecionados (etanólico A. crassiflora, etanólico e aquoso de S. brasiliensis e C. brasiliense), apresentando halos de inibição e concentração inibitória mínima (CIM) para todas as cepas.

Existe uma forma de controle da mastite no rebanho, que é o manejo preventivo, usando técnicas de pré e pós dipping, que consiste em um procedimento de desinfecção dos tetos antes e depois da ordenha, através da aplicação de produto antisséptico, geralmente por imersão dos tetos. Klahr (2016), usou o extrato etanólico de própolis na concentração de 10\% (p/v) como desinfetante alternativo para o manejo de limpeza dos tetos de bovinos e observou que esta solução contribuiu com a melhoria na qualidade microbiológica do leite reforçando que possuíram ação antimicrobiana contra as principais bactérias que causam mastite.

O estudo sobre a atividade antimicrobiana e antibiofilme do cafeato de pentila (C5) e nitrochalcona (NC-E05) contra Staphylococcus aureus e Staphylococcus aureus resistente a meticilina, realizado por Emerí (2018), constatou que tanto a NCE05 quanto a C5 foram capazes de inibir a adesão bacteriana em poliestireno e em células humanas, revelando uma nova opção para o controle de bactérias sem o uso de antibióticos, sendo uma diferente opção para o controle S. aureus.

Filmes a base de gelatina e quitosana foram utilizados por Brazeiro, Moura, Almeida, Moraes e Moura (2018), também com o objetivo de inibir o desenvolvimento dessa bactéria. Estes autores relataram em seu estudo que com a utilização destes filmes não houve crescimento de Staphylococcus aureus, percebemos assim sua ação antimicrobiana contra S. aureus.

Outra diferente possibilidade bastante pesquisada ultimamente está relacionada ao uso de Bacteriófagos líticos, vírus capazes de infectar bactérias. Este controle biológico é realizado por meio da aplicação dirigida de bacteriófagos (ou fagos), que quando entram em contato com bactérias patogênicas específicas, possuem a capacidade de infectá-las e destruí-las (Burrowes, Harper, Anderson, McConville \& Enright, 2011). A utilização da terapia bacteriofágica é relativamente antiga, foi descoberta 
por Francis Twort em 1915 e Felix d’Herelle em 1917, que verificaram agentes terapêuticos potenciais, quando examinou atividade lítica dos bacteriófagos em bactérias específicas (D`HERELLE, 1931 como citado em FANIN et al, 2020, p.25). Leite et al. (2019) isolaram dois bacteriófagos de estábulos que apresentaram uma alta atividade lítica em S. aureus, em ampla gama de estirpes, o que indicou seu potencial para estudos de fagoterapia em gado leiteiro ou como agente de controle biológico para produtos lácteos.

A Ozonioterapia por sua vez é uma forma de tratamento que mistura oxigênio-ozônio mediante a passagem de oxigênio puro por uma descarga elétrica de alta voltagem e alta frequência, tratamento realizado por um equipamento eletromedicina que produz um gás com diferentes concentrações de ozônio. Ao penetrar no organismo, o ozônio melhora a oxigenação consequentemente o metabolismo, contribuindo para a eliminação de produtos tóxicos provenientes do metabolismo celular e regulação dos mecanismos de defesa imunológica, atuando como imunomodulador (Haddad, 2009; Recio Del Pino, 1999 ; Moreira et al., 2014).

Em um estudo realizado por Couto et al. (2016) foi avaliado a eficiência do ozônio sobre a redução da contagem de $S$. aureus, que foram artificialmente inoculados em leite desnatado e integral, as reduções foram significativamente maiores nas amostras a partir dos 20 minutos de ozonização e apresentaram eficácia na redução de $S$. aureus inoculado em leite fluido, sugerindo também que a gordura no leite interfere na ação bactericida do gás.

\section{Considerações Finais}

Conclui-se que o $S$. aureus é uma bactéria gram positiva, de catalase e coagulase também positiva, com alto poder patogênico, que é de difícil controle devido sua alta resistência. O uso de antibiótico é atualmente a forma mais utilizada para o seu controle, entretanto o uso dessa substancia deve ser realizada de forma cautelosa, para evitar a chance de resistência microbiana. Os antibióticos também poder deixar resíduos em produtos de origem animal, e seu alto custo pode ser um problema para o controle de algumas doenças. Devido a essas problemáticas causadas por esse remédio o estudo de outras substâncias que substituam seu efeito se fez necessário, como o uso de óleos essenciais, extrato de plantas, biofilmes, filmes a base de gelatina, controle biológico por bacteriófagos líticos e ozonioterapia.

O óleo essencial de alecrim, alecrim pimenta e capim limão mostraram resultados positivos frente a cepas S.aureus, os extratos de diversos vegetais também obtiveram resultados otimistas. Técnicas como pré e pós dipping com extrato etanólico de própolis, uso de biofilmes, filmes a base de gelatina, controle biológico e ozonioterapia são outras formas que desempenharam efeitos favorável para o controle dessa bactéria.

Um ponto importante antes de iniciar um estudo sobre o uso de óleos essenciais e/ou extratos vegetais é avaliar a incidência da planta na região, devido a impossibilidade de propagar essa planta em outro local. Outro fator importante a ser analisado é a toxidade da planta para o homem e para o animal, se seu uso pode trazer algum risco de intoxicação.

Nota-se nesse estudo uma grande quantidade de tratamentos alternativos para o controle de $S$. aureus, que embora promissoras, implicam em maiores estudos

\section{Referências}

Alegre, M. L., chen, L., david, M. Z., Bartman, C., Susan B.V., Kumar, n., Chong, A. S., \& Daum, R. S. (2016). Impact of Staphylococcus aureus USA300 Colonization and Skin Infections on Systemic Immune Responses in Humans. The Journal of Immunology, 197(4), 1118-1126. https://doi.org/10.4049/jimmunol.1600549

Almeida, M. S. C., Mendonça, R. L., Freitas M. Z. C., \& Vandesmet L. C. (2016). Staphylococcus aureus. Mostra científica em biomedicina, 1 (01). file://C:/Users/Usu\%C3\%A1rio/Downloads/842-2907-1-PB.pdf

Arias, M. V. B. \& Carrilho, C. M. D. M. (2012). Resistência antimicrobiana nos animais e no ser humano. Há motivo para preocupação? Semina: Ciências Agrárias. Londrina, 33 (2), 775-790. https://www.redalyc.org/pdf/4457/445744112039.pdf 
Brazeiro, F. S. G. Moura, J. M., Almeida, L., Moraes, C. C., \& Moura, C. M. (2018). Atividade antimicrobiana de filmes a base de gelatina e quitosana contra staphylococcus aureus. Anais do $10^{\circ}$ SALÃO INTERNACIONAL DE ENSINO, PESQUISA E EXTENSÃO - SIEPE. https://guri.unipampa.edu.br/uploads/evt/arq_trabalhos/18209/seer_18209.pdf

Barrera-Rivas, C., Valle-Hurtado, N., González-Lugo, G., Baizabal-Aguirre, V., Bravo-Patiño, A., Cajero-Juárez, M., \& Valdez-Alarcón, J. (2017). Bacteriophage Therapy: An Alternative for the Treatment of Staphylococcus aureus Infections in Animals and Animal Models. Frontiers in Staphylococcus aureus. $10.5772 / 65761$

Baptista, M. G. F. M. (2013). Mecanismos de Resistência aos Antibióticos. [Tese de mestrado, Universidade Lusófona de Humanidades e Tecnologia]. https://recil.grupolusofona.pt/bitstream/10437/3264/1/Mecanismos\%20de\%20Resist\%c3\%aancia\%20aos\%20Antibi\%c3\%b3ticos\%20-\%20Maria\%20Galv\%c $3 \%$ a3o\%20Ba.pdf

Bassanetti, I., Carcelli, M., Buschini, A., Montalbano, S., Leonardi, G., Pelagatti, P., Tosi, G., Massi, P., Fiorentini L., \& Rogolino, D. (2017). Investigation of antibacterial activity of new classes of essential oils derivatives. Food Control, 73, (B), 606-612. https://doi.org/10.1016/j.foodcont.2016.09.010

Beovic, B. (2006). The issue of antimicrobial resistance in human medicine. International Journal of Food Microbiology. 112(3), 280-287. https://doi.org/10.1016/j.ijfoodmicro.2006.05.001

Boretti, V. S., Corrêa, R. N., Santos, S. S. Ferreira dos, L., M. V. P., \& Silva, C. R.G. (2014). Perfil de sensibilidade de Staphylococcus spp. e Streptococcus spp. isolados de brinquedos de brinquedoteca de um hospital de ensino. Revista Paulista de Pediatria, 32(3), 151-156. https://doi.org/10.1590/01030582201432301

Burrowes, B., Harper, D. ., Anderson, J., McConville, M., \& Enright, M. C. (2011). Bacteriophage therapy: potential uses in the control of antibiotic-resistant pathogens. Expert Review of Anti-Infective Therapy, 9 (9), 775-785. https://doi.org/10.1586/eri.11.90

Castro, K. N. C., Lima D. F., Vasconcelos, L. C., Santos, R. C., Pereira, A. M. L. Fogaça, F. H. S., Canuto, K. M., Brito, E. S., \& Calve, R. M. (2016). Composição química e eficácia do óleo essencial e do extrato etanólico de Alpinia zerumbet sobre Staphylococcus aureus. Arq. Inst. Biol., 83, 1-7. 10.1590/18081657000192014

Chantziaras, I., Boyen, F., Callens, B., \& Dewulf, J. (2013). Correlation between veterinary antimicrobial use and antimicrobial resistance in food-producing animals: a report on seven countries. The Journal of Antimicrobial Chemotherapy, 69 (3), 827-834 https://doi.org/10.1093/jac/dkt443

Costa, C. M. F. C. G. (2018). Resistência aos antibióticos em Staphylococcus aureus: uma revisão [Dissertação de mestrado integrado em medicina, Faculdade de Medicina da Universidade de Coimbra].

Couto, E. P.; Alencar, E. R.; Gonçalves, V. S. P.; Santos, A. J. P.; Ribeiro, J. L.; \& Ferreira, M. A. (2016). Effect of ozonation on the Staphylococcus aureus innoculated in milk. Semina, 37 (4), 1911-1918. https://www.redalyc.org/pdf/4457/445749546045.pdf

Emerí, F. T. A. S. (2018) Atividade antimicrobiana e antibiofilme do cafeato de pentila (C5) e nitrochalcona (NC-E05) em Candida albicans, Staphylococcus aureus e Staphylococcus aureus resistente a meticilina [Dissertação do mestrado, Universidade Estadual de Campinas]. Faculdade Piracicaba, SP.

Fanin, M., Fanin, É. L. B. B., Santos, I. C., Lima, J. S., Gonçalves, A. P. P., \& Martins, L. A. (2020). Métodos alternativos no tratamento de infecções causadas por Staphylococcus aureus. Medicina Veterinária (Ufrpe), 14 (1), 24-32. http://dx.doi.org/10.26605/medvet-v14n1-3711

Gasparotto, P. H., Weber, F. K., Barbosa, V. A. A., Moraes, L. B., Bicalho, B., \& Sobral, F.O. S. (2016). Principais gêneros bacterianos causadores de mastite isolados no Laboratório de Microbiologia Veterinária do Hospital veterinário do Centro Universitário Luterano de Ji-Paraná/RO. Revista Veterinária em Foco, 14 (1), 60-70. http://www.periodicos.ulbra.br/index.php/veterinaria/article/view/2366/2693

Guimarães, D. O., Momesso, L. S., \& Pupo, M. T. (2010). Antibióticos: importância terapêutica e perspectivas para a descoberta e desenvolvimento de novos agentes. Quím. Nova, 33 (3), 667-679. http://dx.doi.org/10.1590/S0100-40422010000300035

Klahr, G. T. (2016). Atividade antimicrobiana in vitro e in vivo do extrato Etanólico de própolis contra as principais bactérias Envolvidas na mastite bovina. [Trabalho de conclusão de curso Graduação em zootecnia, Universidade Federal do Pampa]. Dom Pedrito.

Leite, J. A, Pereira, H. P., Borges, C. A. V., Alves, B. R. C., Ramos, A. I. A. P., Martins, M. F., \& Arcuri, E. F. (2019). Lytic bacteriophages as a potential alternative to control Staphylococcus aureus. Pesq. agropec. bras., Brasília, 54, e00917. https://doi.org/10.1590/s1678-3921.pab2019.v54.00917

Lima, A. L. A., Cruz, A. V., Gonzalez, C. A., Silva, E. A. C., Souza, M. C., Lima, H. K. S., Reis, M. B. C., Costa, R. R., Oliveira, A. L. B., Jesus, I. S., Silveira, J.A. S., \& Silveira, N. S.S. (2020). Perfil de sensibilidade antimicrobiana de bacterias isoladas de leite de vacas com mastite em propriedades de agricultura família. Research, Society and Development, 9 (11). http://dx.doi.org/10.33448/rsd-v9i11.9438

Millezi, A. F., Baptista, N. N., Caixeta, D. S., Rossoni, D. F., Cardoso, M. G., \& Piccoli, R. H. (2014). Caracterização química e atividade antibacteriana de óleos essenciais de plantas condimentares e medicinais contra Staphylococcus aureus e Escherichia coli. Rev. bras. plantas med., 16 (1), 18-24. http://dx.doi.org/10.1590/S1516-05722014000100003

Monteiro, M. V. M. (2017). Avaliar a atividade antimicrobiana de óleos essenciais Citronela (Cymbopogon winterianus) e Andiroba(Carapa guianensis Aubl) em cepas clínicas de Staphylococcus aureus e Escherichia Coli [Trabalho de Conclusão de Curso Graduação em Farmácia, Universidade Federal de Sergipe]. Lagarto-SE.

Moreira, L. H., Moretti A. B. F., Lima C. J., Kozusny-Andreani, D. I., Zângaro, R. A. \& Rodriguez, Z. Z. (2014). Efeitos da aplicação intra-mamária no tratamento de mastite em bovinos utilizando a ozonioterapia. XXIV Congresso Brasileiro de Engenharia Biomédica. 2143-2146. https://www.canal6.com.br/cbeb/2014/artigos/cbeb2014_submission_630.pdf

Pereira, M. D., Oliveira, L. C., Costa, C. F.T, Bezerra, C. M. O, Pereira, M. D., Santod, C. K. A., Dantas, E. H. M. (2020). A pandemia de COVID-19, o isolamento social, consequências na saúde mental e estratégias de enfrentamento: uma revisão integrativa. Research, Society and Development, 9 (7), 5. http://dx.doi.org/10.33448/rsd-v9i7.4548 
Research, Society and Development, v. 10, n. 2, e40310212546, 2021

(CC BY 4.0) | ISSN 2525-3409 | DOI: http://dx.doi.org/10.33448/rsd-v10i2.12546

Pereira, M. N. \& Scussel, V. M. (2017). Resíduos de antimicrobianos em leite bovino: fonte de contaminação, impactos e controle. Revista de Ciências Agroveterinárias. Lages, 16 (2), 170-182. 10.5965/223811711622017170

Ribeiro, I. C. O. (2015). Extratos de plantas do Cerrado com eficácia in vitro contra Staphylococcus spp. e Escherichia coli de bovinos [Dissertação do Curso de Mestrado, Produção Animal Universidade Federal de Minas Gerais].

Silva, A. C., Iacuzio, R., Cândido, T. J. S., Rodrigues, M. X., \& Silva, N. C. C. (2018). Resistência antimicrobiana de salmonella spp., staphylococcus aureus e Escherichia coli isolados de carcaças de frangos: resistência a Antibióticos e óleos essenciais. Revista Brasileira de Agropecuária Sustentável (RBAS), 8 (1), 95-103. https://doi.org/10.21206/rbas.v8i1.474

Silva, D. P., Gellen, L. F.A., Silva, T. S., Costa, J. L., Silva, A. L, Scheidt, G. N. (2013). Resíduos de antibiótico em leite: prevalência, danos à saúde e prejuízos na indústria de laticínios. Evidência. Joaçaba, 13 (2), 127-152. https://core.ac.uk/download/pdf/235126762.pdf

Silva, N., Junqueira, A. C. V, Silveira, A. F. N, Taniwaki, H. M., Gomes, R. A. R, \& Okazaki, M. M. (2017). Manual de métodos de análise microbiológica de alimentos e água (5 $5^{\mathrm{a}}$ ed.). Blucher.

Souza, C. N. Almeida, A, C., Xavier, M. T. R., Costa, J. P. R., Silva, L. M. V., \& Martins E. R. (2017). Atividade antimicrobiana de plantas medicinais do cerrado mineiro frente a bactérias isoladas de ovinos com mastite. Revista unimonte cientifica. Montes Claros. 19 (2). file:///C:/Users/Usu\%C3\%A1rio/Downloads/643-1469-1-PB\%20(1).pdf

Zafalon, L., Filho, A. N., Oliveira, J. V., \& Resende, F. D. (2007). Mastite subclínica causada por Staphylococcus aureus: custo-benefício da antibioticoterapia de vacas em lactação. Arq. Bras. Med. Vet. Zootec, 59 (3), .577-585. http://dx.doi.org/10.1590/S0102-09352007000300005 